vapour at $0^{\circ} \mathrm{C}$. The flame velocity was measured by a photographic method over the $15-30 \mathrm{~cm}$. section of the tube where the speed was already constant. Results obtained with initial pressures of $400 \mathrm{~mm}$. and $200 \mathrm{~mm}$. are shown in Fig. 1. At $400 \mathrm{~mm}$. there are two sharp maxima corresponding to tho mixtures: $2 \mathrm{CO}+\mathrm{O}_{2}$ and $4 \mathrm{CO}+\mathrm{O}_{2}$. At $200 \mathrm{~mm}$. pressure the maximum corresponding to the stoichiometric mixture is smoothed out, whilst that for the $4 \mathrm{CO}+\mathrm{O}_{2}$ mixture remains. It may be noted that the curve for the change of velocity of the detonation wave $D$ taken from the data of Campbell and others, and represented in Fig. 1, also passed through a maximum for the mixture $4 \mathrm{CO}+\mathrm{O}_{2}$.

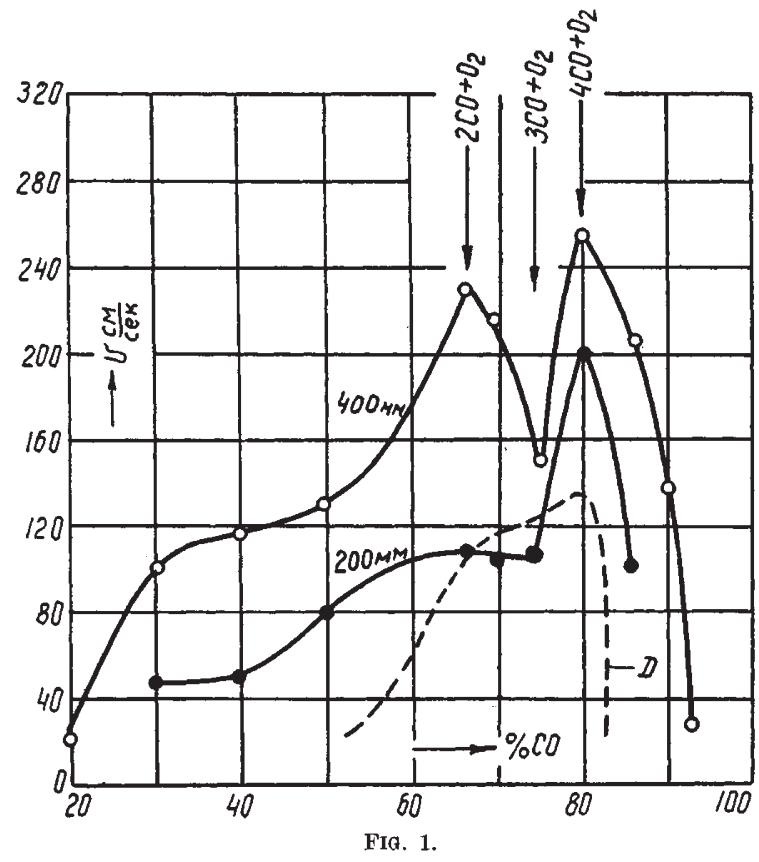

It seems clear to us that the form of the curve for the flame velocity in $\mathrm{CO}-\mathrm{O}_{2}$ mixtures is connected not with the hygroscopic conditions as suggested by Payman and Wheeler, but with a change in one of the main kinetic parameters, namely, the temperature of spontaneous combustion for constant time lag. Unfortunately, no systematic studies in this direction appear as yet to have been made.

V. VORONKOV.

Institute of Chemical Physics, A. SoKolik.

Leningrad.

Jan. 16 .

1 W. Payman and R. I. Wheeler, $J$. Chem. Soc., 1835 (1932)

2 W. A. Bone and J. Bell, Proc. Roy. Soc., A, 143, 1 (1934).

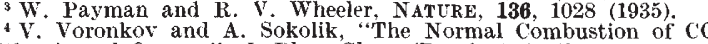
'V. Voronkov and A. Sokolik, "The Normal Combustion of
with Air and Oxygen", J. Phys. Chem. (Russian), in the press.

with Air and Oxygen", J. Phys. Chem. (Russian), in the press. (1933).

\section{Influence of Heavy Water on the Colour of Hydrated Salts}

THE announcement by Joos and Böhm ${ }^{1}$ of the displacement of the absorption lines produced by replacement of the water of crystallisation in potassium chrome selenium alum by heavy water renders it desirable to present a preliminary note on results of a somewhat similar nature which have been obtained here.

The blue colour of the solution obtained by dissolving anhydrous copper sulphate in 99.5 per cent heavy water is noticeably less intense than that of a solution of equal strength in ordinary water. Colorimetric determination shows that a column of $5 \mathrm{~cm}$. of the heavy water solution is matched by a column of $4.1 \mathrm{~cm}$. of the solution in ordinary water. Comparison is difficult, however, due to a difference in tint, the heavy water solution being slightly greener. The absorption spectra of these solutions are under investigation.

The effect is well marked in the solid salts $\mathrm{CuSO}_{4}, 5 \mathrm{H}_{2} \mathrm{O}$ and $\mathrm{CuSO}_{4}, 5 \mathrm{D}_{2} \mathrm{O}$, and these are readily. distinguishable by the difference in tint.

Further work on these salts and other salt deuterates is in progress, and a detailed account will be published in due course.

J AMES BeLL.

University of Glasgow. March 6.

${ }^{1}$ Phys. Z., 36, 826 (1935).

\section{The Gases of War}

Dr. H. Levinstein, in Nature of February 29, has contributed an interesting letter on the manu. facture of mustard gas in England during the Great War, and has objected to my statement that none of British manufacture was actually fired on the Western Front. On the other hand, Fries and West in their book on "Chemical Warfare", p. 153, refer to the French as "the only one of the Allies that manufactured and fired mustard gas", and further state that "the Levinstein process would have been a tremendous gain, had the war continued". Julius Meyer also in "Der Gaskampf" says that it was only made by Germany's enemies towards the end of the War in quite small quantities, and moreover that the French Army was the only one of the Allies that used it. Elsewhere it has been stated that the French transferred to the British such mustard gas as we did fire.

I have not, therefore, been the only one to make this statement, but when we consult those who were in responsible positions in connexion with the matter, it becomes evident that it is incorrect. Thus $\mathbf{M}$. Moureu in "La Chimie et la Guerre" gives a list of the Allies to whom the French sent mustard gas, and Great Britain is not there mentioned. BrigadierGeneral (now Sir) Harold Hartley, who was Assistant Director of Gas Services and Controller of the Chemical Warfare Department, said (J. Royal Artillery, 46, 492 ; 1919-20) : "Our disappointments in 1918 were due to the fact that we did not get mustard gas until the end of September." "Mustard gas was used to a small extent in the preparation for the attack on the Hindenberg Line on September 30th and gave good results. The French had used it first in June with great success." Major-General Foulkes, who commanded the Special Brigade, says in his book "Gas": "We first used mustard gas of our own manufacture on the Fourth Army front on the night of 26th September 1918, when 10,000 shells were fired with very remarkable results."

The incident shows how an erroneous statement may be made and repeated even when everyone is 